Eva Ramón Reyero

Universidad Francisco de Vitoria. Centro de Documentación Europea

@ CDE@ufv.es (iD) 0000-0002-6825-5101

Ascensión Gil Martín

Universidad CEU San Pablo. Centro de Documentación Europea

@ ascension.gilmartin@ceu.es (iD 0000-0002-9274-1847
Recibido / Received 10 de noviembre de 2020

- Aceptado / Acepted 25 de noviembre de 2020

- Páginas / Pages De la 103 a la 118

- ISSN: $1885-365 X$

\title{
Desinformación e infoxicación, dos «falsos sinónimos» frente a la estrategia de información de la Comisión Europea
}

\section{Disinformation and infoxication, two «fake synonyms» in the context of the European Commission's information strategy}

RESUMEN:

La crisis financiera de 2008 extendió el uso del término infoxicación unido al uso intensivo de las tecnologías de la comunicación. En 2016 irrumpen con fuerza dos términos: posverdad y fake news. Han pasado cuatro años y la desinformación es protagonista secundario en la crisis sanitaria del Covid-19 y la crisis socioeconómica consiguiente. La Unión Europea identifica la desinformación como un verdadero peligro para las democracias y diseña un plan de acción.

PALABRAS CLAVE:

Desinformación; Infoxicación; Fake news; Unión Europea; Alfabetización digital; Alfabetización informacional.

ABSTRACT:

The 2008 financial crisis extended the use of the word infoxication in the wake of the intensive use of communication technologies. Two more terms burst onto the scene in 2016: post-truth and fake news. Four years later disinformation has played a supporting role in the COVID 19 pandemic and the ensuing socio-economic crisis. The European Union has flagged up disinformation as a real danger to democracy and has drawn up an action plan in response.

Disinformation; Infoxication; Fake news; European Union; Digital literacy; Information literacy.

\section{Introducción}

La Unión Europea defiende la libertad de expresión tal y como aparece incluido en la Carta de Derechos Fundamentales, al mismo tiempo que actúa en contra de la desinformación por 
considerarla una práctica antidemocrática. En su Plan de Acción de lucha contra la desinformación (Comisión Europea, 2018), plantea una serie de acciones dirigidas a combatir la creciente desinformación y fomentar la alfabetización informacional.

\section{La infoxicación como parte de un ecosistema de desinformación}

El término infoxicación ${ }^{1}$ provoca, en su reacción, la aparición del concepto de desconexión. Sin duda, la infoxicación se produce en un entorno digital, por lo que la mayoría de los consejos dirigidos a evitar sus efectos de estrés, miedo, desinformación, dependencia, etc., pasan por desconectarse durante periodos de tiempo más o menos largos o establecer objetivos de información focalizados sobre temas de interés concretos. Cuestión difícil en un modelo social dirigido a primar el denominado always on y lejos de comprender las razones de la infodieta o desconexión.

Difícil pero posible. La decisión de desconectar en un entorno hiperconectado² cuenta con ejemplos como el de Mar Cabra, periodista y ganadora de un premio Pulitzer en 2017 con solo 33 años. Mar Cabra se confiesa víctima del llamado Síndrome de Burnout o «síndrome del trabajador quemado", provocado por jornadas de teletrabajo sin límite y un uso intensivo de la tecnología. Esta situación la llevó a la hiperconexión, a la infoxicación y a ser víctima de «la economía de la atención: la que hace ganar dinero a las aplicaciones según el tiempo que pasamos en ellas» (Cabra, 2019). Junto con ella, son muchas las personas que recomiendan la desconexión durante unas horas o durante uno o varios días.

Otra dimensión de la infoxicación es el papel protagonista que están adquiriendo los algoritmos en el desarrollo de la inteligencia artificial. Un papel preeminente en cuanto a su influencia en la toma de decisiones. En este contexto, la reciente creación del Observatorio del Impacto Social y Ético de la Inteligencia Artificial (OdiselA https://www.odiseia.org) del que Mar Cabra forma parte dentro de su junta directiva, analiza desde las humanidades este tipo de desafíos.

La infoxicación es, en parte, una consecuencia de la falta de atención crítica hacia el entorno y de una acusada pereza intelectual. Hoy en día, la lectura pausada, la interpretación crítica o incluso el esfuerzo de comprensión que requiere enfrentarse a un texto, son elementos incompatibles con la rapidez que exige la viralización, la instantaneidad demandada por las redes sociales, el creer necesaria la multiconexión y, se podría decir, «lo inmensamente global» de la globalización.

Se crea así la tormenta perfecta: sobre un exceso de información, imposible de asimilar a nivel cognitivo, pero con capacidad de influir a un nivel emocional (posverdad), se suma la aparición de noticias que no responden a la realidad por ser falsas o estar manipuladas

\footnotetext{
1/ El término infoxicación no está en el Diccionario de la RAE, aunque lo relaciona con la entrada: intoxicación. Se trata de un neologismo que se refiere, en un entorno preferentemente digital, a la sobrecarga de información y sus efectos negativos.

2/ El término hiperconectado no está en el Diccionario de la RAE, aunque lo relaciona con conectar. Se trata de un termino que refleja la conexión a la información a través de medios electrónicos, especialmente a través de internet y que está teniendo un mayor impacto con internet de las cosas.
} 
(desinformación) y que llevan implícito un grado de alarmismo tal, que apela directamente al miedo, emoción que atrapa la mirada y que, sin saberlo, consume publicidad ad hoc.

Hay 8 emociones basadas en la clasificación de Plutchik: alegría, confianza, miedo, sorpresa, tristeza, aversión, ira y anticipación, y una lista de unos 32.000 hashtags de Twitter cada uno con sus asociaciones a estas mismas emociones. Las emociones expresadas en respuesta a falsedades ayudan a conocer qué factores (además del efecto «nuevo contenido») están implicados en la decisión de compartir noticias falsas. Aunque no podemos afirmar que la novedad provoque un retuit o que la novedad sea la única razón por la que las noticias falsas se retuitean, es frecuente encontrar cómo las noticias falsas son más novedosas y que es más probable que la información nueva sea retuiteada (Vosoughi, Roy y Aral, 2018).

La dramatización se abre paso frente a un lenguaje conscientemente ambiguo que es propio de ciertos sectores. Por ejemplo, en el ámbito político de la diplomacia, tradicionalmente unido a la prudencia de sus mensajes, a una «ambigüedad constructiva elegida frente a la precisión, a la razón frente a la pasión y a la confidencialidad frente a la transparencia» (Bjola, 2019). En las redes sociales, lo políticamente correcto se diluye en un espacio digital donde los datos y los algoritmos tienen su propio lenguaje. Un lenguaje que mezcla imágenes junto a emociones, y referentes cognitivos en pro de contenidos semánticos, muchas veces, bajo nuevas reglas. Un lenguaje en el que la llamada de atención emocional, visual, inmediata y simple es la clave para conseguir que, como apunta Bjola, los contenidos digitales de las plataformas de redes sociales se adapten a estos medios y consigan así contenidos virales.

La ciudadanía no se siente capaz de desconectar. En el fondo, se siente emocionalmente atrapada en esa vorágine de noticias al instante y aunque la mayoría puedan estar localizadas en el otro extremo del planeta, la inmersión emocional que se produce junto con el volumen de información y su bien diseñada complejidad, invita a abandonar cualquier intento de comprensión individual, en favor de prácticas comunes: «no lo leo pero lo paso a mis contactos porque parece importante», «luego lo leo, pero primero lo paso a mis contactos antes de que me llegue por otro grupo» que no dejan de tener consecuencias. Así, Vosoughi, Roy y Aral advierten que:

Si el rumor A es tuiteado por diez personas por separado, pero no retuiteado, generará 10 cascadas, cada una de tamaño 1 . Por el contrario, si el segundo rumor $B$ es tuiteado independientemente por dos personas, y cada uno de esos tuits es retuiteado 100 veces, el rumor alcanza dos cascadas, pero cada una con cien ítems (Vosoughi, Roy y Aral, 2018).

En esa autoexigencia de rapidez de reacción, en ese cansancio provocado por la decisión de conexión 24/7, es fácil caer en el «todo vale», pasando de leer entre líneas a ni siquiera leer el titular, por la prisa necesaria de cliquear compartir, viralizar, y cumplir con la pequeña tarea de informar a los contactos de redes.

La hiperconexión, la infoxicación, se traduce en un déficit de atención inducido que alcanza un nivel perfecto de retroalimentación: cuanta más conexión y más consumo de información, menos capacidad de atención y por tanto menos capacidad de discernimiento. Nuestro dedo en la pantalla se convierte en nuestro cerebro, pero sin reconocimiento ni razonamiento, sin pensamiento, y mucho menos pensamiento crítico, ante lo que nuestros ojos «tragan». La emoción de la posverdad deja que las palabras, las imágenes, o que los hashtags, sean los 
que conecten con emociones básicas de preocupación, de tristeza, y son más rápidamente viralizados que los que conducen a emociones positivas.

En línea con el necesario trabajo con las grandes plataformas, el uso globalizado de las aplicaciones que diseñan, la captación sistemática de datos personales y la precaución necesaria ante las potenciales amenazas de la inteligencia artificial en una sociedad hiperconectada, surge el concepto de diplomacia tecnológica como modelo multinivel para trabajar a nivel gubernamental, económico y social buscando limitar los efectos nocivos y potenciar los beneficios de las tecnologías de la información y de la inteligencia artificial:

Como otras tecnologías de la información y las comunicaciones, la inteligencia artificial puede ser vista como un sistema multinivel con capas tecnológicas, organizativas y sociales que interactúan en procesos tanto de abajo hacia arriba (bottom-up) como de arriba hacia abajo (top-down). La diversidad y vitalidad de estas iniciativas podría estimular un proceso de inspiración y construcción mutua, así como de aprendizaje. Sin embargo, al mismo tiempo existe un vacío en lo que sería una capa de participación, de implicación de la sociedad civil, y que lo haga de forma sostenida e integrada. Lo que falta es un diálogo internacional - permanente y no a impulsos- que permita llevar hacia adelante conversaciones y espacios de discusión entre todos los interesados. Su fin sería construir una meta narrativa que realmente trate de forma amplia los aspectos económicos, legales, sociales, éticos y en derechos humanos de la inteligencia artificial, de manera que realmente alinee las virtudes de la inteligencia artificial para el bien común. Suena complicado, pero es factible. Creemos que éste es precisamente el nuevo rol para el proceso que llamamos «diplomacia tecnológica» (Feijóo, 2020).

\section{Desinformación vs. fake news}

Fake news es el término más difundido, el más conocido de una nube de terminología que incluye: fake news, false news, rumores en cascada, posverdad, rumores, etc. Y lo cierto es que todos estos términos contribuyen en la misma medida a la infoxicación a la que la ciudadanía se ve expuesta. La Comisión Europea, en línea con el criterio marcado por las investigaciones en comunicación (Rodríguez Pérez, 2019), considera más adecuado el uso de términos menos confusos. Fake news se puede definir como una noticia falsa, una mentira o como un ataque u opinión política contraria a una línea de pensamiento, implicando una intención clara de distorsionar la verdad. Quizá se sumen en un mismo término demasiados significantes. Para la Unión Europea la desinformación:

Se define como «información verificablemente falsa o engañosa que se crea, presenta y divulga con fines lucrativos o para engañar deliberadamente a la población, y que puede causar un perjuicio público". El perjuicio público incluye las amenazas a los procesos democráticos, así como a bienes públicos tales como la salud, el medio ambiente o la seguridad de los ciudadanos de la Unión. La desinformación no incluye los errores involuntarios, la sátira y la parodia, ni las noticias y comentarios partidistas claramente identificados. Las acciones incluidas en el presente Plan de Acción solo se dirigen a los contenidos de desinformación que tienen carácter legal con arreglo a la legislación nacional o de la Unión y se entenderán sin perjuicio de la legislación de la Unión o de cualquiera de los Estados miembros que pueda ser aplicable, incluidas las normas sobre contenidos ilícitos (Comisión Europea, 2018: 1). 


\section{Desinformación y medios de comunicación}

Cuando se desmonta una noticia falsa, una imagen falsa, cuando se razona de manera pausada sobre la desinformación y sus malos trucos, no hay forma de no sentir una sensación de ridículo, siempre justificado por exceso de información, la infoxicación a la que somete la actualidad, los medios, la política, grupos de presión, etc.

Por ejemplo, en referencia al tratamiento informativo de la oleada de contagios generado por la Gripe-A en 2009, su análisis desprende la idea de desconfianza hacia los profesionales y medios por parte de una sociedad que, aunque tiene acceso a la información, carece colectivamente de la voluntad para dedicarse a su comprobación. (Nino González, Barquero Cabrero y García García, 2017: 88). Un modelo que parece que se repite una y otra vez ante crisis de diversa índole.

Así, en el año 2015, el Consejo Europeo alertó de la existencia de campañas de desinformación que, con origen ruso, buscaban desestabilizar el avance democrático de algunos países del Este de Europa, como en el caso de Ucrania. El Servicio Europeo de Acción Exterior enmarca estas campañas en lo que se denominan amenazas híbridas y que incluyen la confusión de la ciudadanía mediante desinformación en conflictos militares o políticos (Comisión Europea, 2016a). En 2016 creó el grupo de trabajo East StratComm (https://eeas.europa.eu/ headquarters/headquarters-homepage/2116/-questions-and-answers-about-the-east-).

La desinformación puede ser un arma desestabilizadora en procesos democráticos. $Y$ aquí se puede citar como ejemplo el papel de la Agencia de Investigación de Internet en las elecciones presidenciales de Estados Unidos en 2015; el referéndum sobre la permanencia en la UE celebrado en Reino Unido en 2016 y el escándalo de Cambridge Analytica, entre otros. Parece que pocas son las lecciones aprendidas cuando están saltando todas las alarmas ante la gestión de los resultados de las elecciones presidenciales de Estados Unidos, que ha sido récord en desinformación en las primeras 24 horas de escrutinio.

La OTAN realizó en el verano de 2019 un experimento centrado en el mercado negro de la manipulación en redes sociales y su profesionalización. Entre las prácticas que analiza el informe están la de creación de cuentas falsas, la inclusión de contenidos falsos, comentarios o likes falsos, o la compra de estos para aumentar los resultados, a lo que hay que añadir la velocidad de difusión. Finalmente, la revisión y cierre de cuentas falsas o manipuladas, algo que parece ser todavía cuesta mucho en la dinámica de las grandes plataformas (Bay y Fredheim, 2019).

El mercado de la publicidad basa parte de su éxito en el número de clics de un usuario promoviendo contenidos sensacionalistas y virales. «Esto facilita la colocación de anuncios en sitios web que publican contenido sensacionalista que apela a las emociones de los usuarios, incluida la desinformación» indica el informe publicado por el Global Disinformation In$\operatorname{dex}(\mathrm{GDI}, 2019)$.

El contexto de la crisis del Covid-19 es sumamente ilustrativo de esta práctica. Los cálculos realizados por el GDI (2020) al respecto concluyen cómo el beneficio obtenido por unos 500 sites de contenidos de desinformación relativos al Covid-19, en lengua inglesa, ascendió a 25 millones de dólares entre enero y junio de 2020. Y todo ello con una sencilla estrategia: Un medio de comunicación presente en la Web publica una noticia sensacionalista, dramatizada, falsa, un rumor o como se quiera denominar. Y lo hace incluyendo o insertando publici- 
dad comercial. El resultado es que millones de personas acceden, se sienten impactados por esa noticia e inmediatamente viralizan este contenido, a la vez que consumen publicidad de conocidas marcas comerciales que han pagado por aparecer ahí.

\section{Desmontando contenidos falsos: informar sobre la desinformación}

\subsection{El papel de la Unión Europea}

Esta tarea de toma de conciencia frente a la desinformación se está realizando en distintos niveles. La Comisión Europea en 2018 define la desinformación en línea como: algoritmos basados en criterios de negocio de las grandes plataformas digitales. Privilegian contenidos sensacionalistas facilitando su difusión entre usuarios afines. Los algoritmos aumentan indirectamente la polarización y refuerzan los efectos de la desinformación, alertando sobre la existencia de servicios automatizados, o bots, que «amplifican la difusión de desinformación» y llegan a facilitar la creación de cuentas falsas con potencial masivo. Aquí la Comisión recalca cómo:

Los propios usuarios, también desempeñan un papel en la difusión de desinformación, que tiende a viajar más rápidamente en las redes sociales, debido a la propensión de los usuarios a compartir contenido sin verificarlo previamente. El volumen y la velocidad, cada vez mayores, del flujo de contenido en línea, aumenta el riesgo de compartir desinformación indiscriminadamente (Comisión Europea, 2018).

Proponiendo como soluciones a la desinformación: transparencia en cuanto al origen; diversidad conducente a un pensamiento crítico y a un periodismo de calidad; alfabetización mediática; credibilidad y trazabilidad de la información; participación de autoridades, plataformas en línea, anunciantes, medios de comunicación y ciudadanía.

En abril de 2018 la Dirección General Connect (Redes de comunicación, contenido y tecnologías) de la Comisión Europea, hizo pública una consulta pública sobre la circulación de fake news y de desinformación a través de medios online. La petición de autorregulación por parte de los medios de comunicación y la necesidad de igualar las condiciones entre los productores de contenidos y las plataformas sociales vía nueva reglamentación, fueron unas de las conclusiones del estudio.

EUvsDisinfo (https://euvsdisinfo.eu/disinformation-cases) es otra web en la que se analiza la desinformación relacionada con la Unión Europea, y especialmente en relación con lo concerniente a los países del Este de Europa y el área de influencia rusa. Fue creada en 2018 y cuenta ya con casi 10.000 noticias analizadas.

Más recientemente se ha creado el Observatorio Europeo de Medios Digitales, (https:// edmo.eu) que desde junio de 2020 aglutina espacios de investigación de universidades, junto con líderes de opinión y la creación de un hub para fact checkers, con el objetivo de limitar la desinformación en la UE.

La tarea de la Comisión en esta línea se centra en mejorar la detección de desinformación y analizar sus elementos; proteger la integridad democrática de procesos electorales; des- 
mentir noticias relacionadas con mitos sobre la UE a través de los servicios de las Representaciones de la Comisión en los distintos Estados miembros; trabajar bajo el criterio de alerta temprana en todos los Estados (Rapid Alert System, RAS); cooperar con las plataformas online sobre la base de lo establecido en el Código de Buenas Prácticas contra la desinformación; promover la alfabetización digital y empoderar a la sociedad civil.

La propia Comisión ha creado una web dirigida específicamente a recoger la infodemia, la desinformación en el contexto de la crisis del Covid-19 (https://ec.europa.eu/info/live-worktravel-eu/health/coronavirus-response/fighting-disinformation_en).

\subsection{La implementación del Código de buenas prácticas frente a LA DESINFORMACIÓN}

La Comisión Europea busca la adhesión de empresas y asociaciones a los objetivos y compromisos incluidos en el código y que permitirán identificar las acciones necesarias para luchar contra la desinformación. A saber, y tal como se incluye en el texto del Código:

- Análisis de la colocación de anuncios publicitarios para controlar con ello la capacidad económica de los creadores de desinformación. Los signatarios podrán interrumpir la publicidad, limitar la inserción de anuncios de pago y verificar los datos.

- Publicidad dirigida o publicidad política que tendrá que garantizar la transparencia. Los signatarios tendrán que atenerse a lo establecido por el derecho de la UE y sus códigos de autorregulación.

- Integridad de los servicios, centrada fundamentalmente en la importancia de cerrar cuentas falsas, y establecer sistemas de marcado para emisores zombis asegurando que no puedan confundirse con interacciones humanas.

- Capacitación de los consumidores. Diluyendo la visibilidad de la desinformación mediante la capacitación para saber distinguir contenidos fiables.

- Capacitación de la comunidad investigadora. Verificación de datos de investigación, facilitar investigaciones independientes.

Anualmente la Comisión publica un informe de autoevaluación en el que participan signatarios como Mozilla, Facebook, Google, Microsoft, Twitter, etc. El último publicado por la Comisión y fechado en septiembre de 2020 agradece los esfuerzos de las plataformas online y de las empresas de publicidad por las medidas de autorregulación aplicadas, los retos pendientes y las limitaciones en la regulación de la desinformación. En sus conclusiones señala:

Es una herramienta única e innovadora, con repercusión internacional que fomenta la cooperación con socios como Australia o Canadá y ha creado una estructura de cooperación con las grandes plataformas online. [...] El Código deberá mejorar en la definición más clara de conceptos, procedimientos y en la transparencia de indicadores y monitorización. Además, deberá de implicar en mayor medida al sector de la publicidad. Ha de presentar un modelo más estructurado de cooperación entre la comunidad investigadora y las grandes plataformas (Comisión Europea, 2020a: 19). 


\subsection{ENTIDADES Y ORGANISMOS EN LA LUCHA CONTRA LA DESINFORMACIÓN}

Además de la Unión Europea, y contando la participación de las entidades y organismos firmantes del Código contra la desinformación, existen institutos de investigación independientes como los ya nombrados, OdiselA y Global Disinformation Index. Son plataformas de profesionales o asociaciones formadas por personas implicadas en la lucha contra la desinformación. Como ejemplos, hay que destacar:

- Provenance (https://www.provenanceh2020.eu) está formada por un consorcio que desde diciembre de 2018 aúna entidades y organizaciones en el desarrollo de herramientas de verificación aplicables a público general y a creadores de contenidos. Su compromiso se basa, según la declaración de marzo de 2020 , en combatir el fraude en la información y la desinformación.

- SOMA (https://www.disinfobservatory.org) (Social Observatory for Disinformation and Social Media Analysis), formado por miembros independientes que tienen como objetivo apoyar la UE en su lucha contra la desinformación.

- En España, Maldita (https://maldita.es) es una herramienta periodística que desmiente contenidos falsos en los medios de comunicación.

También existen aplicaciones útiles para detectar desinformación como la búsqueda inversa de imágenes de Google que ofrece información sobre los metadatos de una imagen (fecha, lugar, fuente original) o colores, manipulación a la que se ha sometido, etc. O el fake check como acción de comprobar los datos antes de ser publicados por los medios de comunicación, un sistema de verificación que puede prevenir desinformación y actuar ante medios de información de baja calidad.

\subsection{El papel de la ciudadanía}

Importante apelar a la responsabilidad de la ciudadanía y su uso de las redes sociales. La Comisión Europea ha realizado dos consultas ciudadanas en torno a este tema. Por un lado, el Eurobarómetro especial (EB 452) (Comisión Europea, 2016b), en el que se mostraba cómo una ligera mayoría entre las personas entrevistadas confiaba en la veracidad de la información que ofrecían los medios de comunicación en la UE28 33 (53\%) descendiendo el porcentaje a un $38 \%$ para España, mientras que respondiendo a la pregunta de confianza o fiabilidad en los medios sociales (redes sociales en internet), las respuestas afirmativas sumaban tan solo un $32 \%$ para la UE28 y un $26 \%$ para España.

En marzo de 2020, un Eurobarómetro especial, (EB 503) estuvo dedicado al efecto de la digitalización en nuestras vidas (Comisión europea, 2020b). La entrevista incluye dos preguntas sobre las noticias falsas y la desinformación. Las respuestas muestran cómo el $61 \%$ de las personas entrevistadas en la UE27 y el 60\% de las personas entrevistadas en España, manifiestan la opinión de que la responsabilidad de combatir las noticias falsas y la desinfor-

3/ UE28 incluyendo Reino Unido. UE27, sin incluir Reino Unido. 
mación es de los medios de comunicación. Y la opinión sobre responsabilidad de las autoridades públicas en este tema tiene más peso entre las personas entrevistadas en la UE27, con un $53 \%$, cuando para España alcanza tan solo el $27 \%$.

A la pregunta de con qué frecuencia se encuentran las personas entrevistadas con noticias o información que creen que distorsionan la realidad o que son falsas, las respuestas se agrupan en: cada día con un $27 \%$ UE27 y un $45 \%$ ES; al menos una vez a la semana con un $25 \%$ UE27 y un $21 \%$ ES.

Destaca cómo la confianza en los medios de comunicación mostrada en la encuesta de 2016 se transforma en 2020 en una petición implícita de control de la desinformación a esos mismos medios. Sin olvidar, aunque en mayor medida en otros Estados de la UE, la demanda de participación en este control de las autoridades españolas. Y ¿cómo creen las personas encuestadas que deben actuar? El $46 \%$ de las respuestas UE27, (43\% para España) quieren que ayuden a los ciudadanos a identificar mejor la desinformación. El 36\% UE27 (35\% para España) piensan que deben apoyar el pluralismo informativo y el periodismo de calidad. Regular las plataformas de redes sociales para reducir la desinformación y apoyar los servicios de verificación de hechos (fact-checking) están ligeramente por encima de estos últimos porcentajes (38 y $37 \%$ respectivamente para UE27 y 34 y $31 \%$ respectivamente para España).

Desde el punto de vista individual, hay también elementos de verificación a tener en cuenta antes de «retuitear o viralizar» a la lista de contactos. Detalles como el titular de la noticia (si es llamativo, o difícil de creer); la autoría (cuando no la hay o procede de un medio desconocido); la exclusividad (o que no aparece en más medios); el formato (colores muy saturados, tamaño de letra... que llaman la atención); la fecha (o no está o es muy antigua); la redacción (con errores gramaticales o de expresión); imágenes fuera de contexto, o de baja calidad; links que dan error y finalmente el contenido basado en hechos que son imposibles de verificar. Se trata de elementos de alerta que pueden retener la desinformación.

El Código de buenas prácticas habla de la capacitación de los consumidores «mediante la mejora de la capacidad de encontrar contenido fiable [...] y facilitar el descubrimiento de contenidos» (Comisión Europea, 2018).

\section{Transparencia, información y fortaleza democrática en la Unión Europea}

\subsection{El Principio de transparencia en la Unión Europea}

La Unión Europea mantiene una política de transparencia que redunda en una forma de comunicación y de información basada en el objetivo de llegar a lo local. Las instituciones, organismos y agencias de la UE ofrecen ruedas y notas de prensa muy completas, con enlaces que permiten ampliar los datos y el contacto directo con las personas responsables de la noticia.

La inmersión en medios sociales es otra característica de la forma de comunicar de las instituciones. Tanto los servicios de prensa como el Colegio de Comisarios, miembros del Parlamento Europeo, etc., disponen de cuentas en Twitter, Instagram, o en otras redes sociales comunes en el ámbito europeo. 
El Portal Europa es la página oficial de la UE, el lugar desde donde se puede consultar toda la información acerca de su historia, instituciones, los derechos ciudadanos, las políticas, oportunidades de financiación, legislación, jurisprudencia, publicaciones, estadísticas, convocatorias de investigación y financiación, notas de prensa, imágenes, vídeos y televisión, en más de un millón de sites incluidos en el dominio: https://europa.eu/

Todo ello, bajo un criterio de acceso abierto, gratuito, multilingüe y podría decirse, inmediato puesto que los contenidos del portal se actualizan diariamente, presentando una estructura que permite navegar, consultar los últimos documentos o comunicados, solicitar documentación de archivo o de los registros de las instituciones y acceder a material divulgativo.

Las instituciones de la UE también han sabido reaccionar como emisores de datos ante la desinformación. Prueba de ello es la página de la Secretaría de Acción Exterior y Política de Seguridad o la página referente a la crisis del Covid-19 ya mencionadas, dirigidas cada una de ellas en su ámbito de actuación, a desmentir y aclarar desinformación producida por distintos medios.

La política de transparencia incluye según la Declaración 17 del Tratado de Maastricht de 1992 «el proceso de decisión como elemento que refuerza el carácter democrático de las instituciones y la confianza del público en la administración” (Ramón Reyero, 2020: 29) y añade, según el artículo 255 del Tratado de Ámsterdam que la ciudadanía de la Unión y las personas físicas o jurídicas con domicilio social en cualquier Estado miembro tiene derecho a acceder a los documentos de las instituciones (Unión Europea, 1999).

El Portal Europa (https://europa.eu) es una muestra de este objetivo de transparencia, y donde se ven reforzados con una estructura de comunicación presente en todo el territorio europeo a escala nacional y local. El principal objetivo es que la ciudadanía comprenda las políticas europeas de forma que tenga en su mano participar en el debate de estas y el utilizar su aplicación con criterios de cohesión, por lo que la estructura en red es la más adecuada para el cumplimiento de este objetivo. En el nivel nacional, las Representaciones de la Comisión Europea presentes en cada Estado miembro dependen de la Dirección General de Comunicación de la Comisión y tienen una importante labor de enlace con los medios de comunicación de cada Estado, incluyendo en su estructura un servicio de prensa. También actúan facilitando la comprensión de las políticas europeas por parte de las instituciones nacionales, empresas y ciudanía.

Entre las acciones de la Representación de la Comisión Europea en España está el escaneado diario de las redes sociales o la identificación y puesta en marcha de rebuttals (o refutaciones) en redes sociales, la elaboración de artículos informativos sobre distintos temas de actualidad de la UE y la colaboración con influencers y con fact-checkers. Mantienen también un acuerdo con el Observatorio Europeo contra la desinformación en España, con socios internacionales como la Organización Mundial de la Salud o la OTAN y a nivel local, cuentan con el apoyo de las redes de información europea en España, especialmente, la red Europe Direct.

\subsection{LAS REDES DE INFORMACIÓN EUROPEA}

La Dirección General de Comunicación de la Comisión Europea es la responsable de la red Europe Direct (https://europa.eu/european-union/contact/europe-direct-answering-your-ques- 
tions-about-eu_es) coordinando más de setecientos puntos independientes de información en toda la UE. La red Europe Direct incluye los EDIC, centros de información Europe Direct, alojados en su mayoría en organismos públicos con el objetivo de ofrecer información al público general. Los EDIC tienen un papel clave en el debate local y regional sobre la Unión Europea, participan en medios de comunicación y se configuran como canal de retorno hacia las instituciones para la opinión pública. En España la red cuenta con cerca de 37 EDIC.

La red Europe Direct incluye también los Centros de Documentación Europea, CDE. Los CDE se crean en 1963 mediante la firma de convenios entre las universidades que los acogen y la Comisión Europea. En la actualidad hay más de 300 universidades en toda la UE que cuentan con un Centro de Documentación Europea, 34 de ellas en España. Los CDE cuentan con personal experto en temas europeos, y tienen como objetivo apoyar la investigación en temas europeos y promover el debate sobre la UE y sus políticas. Ofrecen información y formación en recursos de la Unión Europea, ya sean estos documentos, bases de datos, convocatorias, etc., y en cuestiones relacionadas con el proceso de integración. Además, atienden peticiones de información del público general, empresas y medios de comunicación, entre otros. Los CDE participan en proyectos comunes que desarrollan entre varios centros, a nivel nacional y europeo. El $96 \%$ de sus fuentes de información son publicaciones oficiales de la Unión Europea y el 94,3\% de las web son páginas oficiales de la UE seguido de monografías y revistas científicas (86,1\%) (Katsirikou, Rigakou y Giannopoulou, 2019: 7).

La red Europe Direct, al igual que otras redes especializadas dependientes de la Comisión Europea, permiten que cualquier persona encuentre un enlace con la información europea, a nivel local y en su propia lengua, en el que será atendido por personal experto (https:// centro-documentacion-europea-ufv.eu/redes-de-informacion-de-la-union-europea)

\section{Alfabetización digital}

Partiendo del concepto de alfabetización informacional reconocido por la Asociación de Bibliotecas Americanas en 1989 y definido como reconocer y tener la habilidad de localizar, utilizar y evaluar la información, la evolución del concepto (Sample, 2020) desemboca hoy en día en el término de alfabetización digital. $Y$ es que en la actualidad se ha buscado incluir en este concepto nuevos elementos que integren el cambio de paradigma tras la incorporación de las tecnologías de la información, las redes sociales y los medios digitales. Por ello, la alfabetización informacional abarca hoy espectros más amplios de forma que:

\footnotetext{
Sea entendida como un proceso. Una información que es dinámica, generada y compartida continuamente, es el objeto de estudio de la meta alfabetización: la habilidad de adquirir críticamente diferentes competencias y reconocer una necesidad de alfabetización integrada en el ecosistema de información es una meta alfabetización (Mackey y Jacobson, 2014: 2).
}

Una meta alfabetización que debería de incluir la adquisición de competencias al modo de la alfabetización informacional, pero dentro del ecosistema digital. Una new media literacy necesaria para el acercamiento a las tecnologías de la información y la formación de criterio frente a la desinformación (Borges y Marzal García-Quismondo, 2017). 


\subsection{Los Centros de Documentación Europea y la alfabetización INFORMACIONAL Y DIGITAL}

A pesar del compromiso de transparencia de la UE o precisamente debido a ello, la documentación de la UE puede verse como un ecosistema de dimensiones inabarcables. Un Centro de Documentación Europea puede perfectamente generar casi doscientos mails en los que referenciar más de trescientos documentos para responder la consulta realizada por una sola persona que se encuentre trabajando en su tesis doctoral (Steletti y Mestre, 2017: 5).

La actualización de conocimientos mediante reuniones de formación anual, el manejo experto de las bases de datos europeas, registros de transparencia, archivos, etc., y de los documentos que generan las instituciones, asegura una experiencia interdisciplinar en torno al proceso de integración europea y sus políticas.

Los Centros ofrecen información de la UE también a través de sus redes sociales. En 2019 , del total de la red, el 75,4\% mantenía una página web propia y el $47,5 \%$ tenía presencia en alguna red social desde la que ofrecían información sobre temas europeos. (Katsirikou, Rigakou y Giannopoulou, 2019: 7). De manera presencial, los Centros incluyen en sus servicios de información, consultas sobre la UE a la vez que elaboran material divulgativo de referencia y/o publicaciones.

Desde hace unos años, según estos mismos autores, los Centros asumen labores clave en alfabetización informacional y digital, correspondiéndose esta actividad con el $56,6 \%$ de su trabajo dentro de la universidad, ya sea mediante cursos o sesiones organizadas por el propio Centro o participando en otros cursos, grados o postgrados. Añadir la participación en debates/diálogos ciudadanos \#EUDialogues, como por ejemplo el organizado por el Instituto de Estudios Europeos junto con el Centro de Documentación Europea de la Universidad CEU San Pablo en octubre de 2017 (https://www.youtube.com/watch?v=kmKy6NWC0og)._Estos debates son promovidos por las instituciones europeas y muchos de ellos en colaboración con Centros de Documentación Europea.

Con respecto a la desinformación, la Comisión Europea ha remarcado cómo los ciudadanos deben conocer mejor la información sobre la Unión Europea para poder así entender mejor las decisiones de las instituciones. Y esta es precisamente una de las tareas de la red de Centros de Documentación Europea.

\subsection{Competencias digitales en la Unión Europea}

El curriculum europeo EUROPASS (https://europa.eu/europass/es/how-describe-mydigital-skills) incluye desde hace años la descripción de las competencias digitales, de acuerdo con el documento llamado DigComp (Digital Competence Framework for citizens) resultado del trabajo de un grupo multidisciplinar con participación de representantes y personas expertas de varios Estados miembros (https://ec.europa.eu/jrc/en/digcomp) (Vuorikari et al., 2016) que incluye cinco competencias de las cuales, las primeras definen:

- Tratamiento de la información: buscar información online utilizando motores de búsqueda, comparando distintas fuentes para poder evaluar la validez y credibilidad de la información, así como guardar la información en los medios más adecuados. 
- Creación de contenido: producir contenidos digitales, aplicando el formato adecuado y respetando las licencias y copyright.

- Comunicación: comunicar en varias aplicaciones, compartir archivos y contenidos, manejar herramientas de colaboración, transmitir conocimientos online bajo las normas básicas de netiqueta (DIGCOMP 2.0)

La complejidad de informaciones en el entorno digital parece recomendar la extensión de adquisición de este tipo de competencias no solo en ámbitos profesionales dirigidos a la comunicación o la información, sino que deberían tomarse como competencias básicas y transversales al alcance de cualquier tipo de usuario de medios online.

\section{Conclusiones/Discusion}

Si bien el fenómeno denominado desinformación cuenta con una trayectoria histórica, es precisamente en estos últimos años cuando la presencia de medios y redes sociales experimenta un crecimiento exponencial que inmerso en un entorno de infoxicación, se constituye como una verdadera preocupación para el correcto funcionamiento de las democracias.

Desde 2015 las amenazas híbridas han provocado momentos de riesgo en distintos procesos democráticos pero las lecciones aprendidas en la crisis del Covid-19 deben generar un sistema de prevención y alerta en instituciones públicas y medios de comunicación capaz de defender a la ciudadanía de los riesgos de la desinformación.

Iniciativas y estrategias de comunicación como la de la Unión Europea parecen tener potencial suficiente como para pensar que se están abriendo vías de trabajo que podrían demostrar su eficacia contra la desinformación: la negociación con las grandes plataformas de comunicación, la apuesta por la alfabetización digital, el refuerzo de la política de transparencia y de información a la ciudadanía de los procesos de decisión europeo.

La iniciativa de entidades particulares, institutos de investigación etc., que siguen esta estela de visibilizar el problema, analizar riesgos y detectar desinformaciones, resultan muy útiles para tomar conciencia de su alcance, así como de liderar la lucha contra sus efectos.

Los medios de comunicación deben aplicar el fact checking para seguir contando con la confianza de la ciudanía y ofrecer su colaboración en la lucha contra la desinformación.

Los Centros de Documentación Europea y otras redes de información de la UE son un punto de referencia en la alfabetización informacional y digital sobre el proceso de integración y las políticas europeas.

La ciudadanía ha de asumir de manera individual su propia responsabilidad en la comprensión y en la identificación de la desinformación. En esta línea, profesionales de la información y de la comunicación, deberán intensificar su labor de alfabetización digital, mejorando así las capacidades personales de lucha contra la desinformación.

\section{Bibliografía}

ACCENTURE (2020). The human impact of data literacy: a leader's guide to democratizing data, boosting productivity and empowering the workforce. Report 2020. Recuperado de https://www.accenture. com/_acnmedia/PDF-115/Accenture-Human-Impact-Data-Literacy-Latest.pdf 
ALONSO, Patricia (2017). «Fake news y posverdad en tiempos de populismos: lecciones para periodistas». Cuadernos de Periodistas, 34, 77-84. Recuperado de http://www.cuadernosdeperiodistas. com/media/2017/07/Patricia_Alonso.pdf

BAY, Sebastian y FREDHEIM, Rolf (2019). Falling Behind: how social media companies are failing to combat intauthetic behaviour online. Riga (Latvia): NATO. Strategic Communications Centre of Excellence. Recuperado de https://cutt.ly/LjzuTN6

BJOLA, Corneliu (2019). «In virality we trust! The quest for authenticity in digital diplomacy». ARI Real Instituto Elcano, 83. Recuperado de https://cutt.ly/vjztSZA

BORGES, Jussara y MARZAL GARCÍA-QUISMONDO, Miguel Ángel (2017). «Competencias en información y en comunicación: desarrollo conceptual a partir de la New Media Literacy». Revista interamericana de bibliotecología, 40(1), 35-43. Recuperado de http://www.scielo.org.co/pdf/rib/ v40n1/0120-0976-rib-40-01-00035.pdf

CABRA, Mar (2020). "Cuando la mente cae esclava de la tecnología». El País, 27 de junio. Recuperado de https://elpais.com/tecnologia/2020-06-27/cuando-la-mente-cae-esclava-de-la-tecnologia.html

COMISIÓN EUROPEA (2016a). Comunicación conjunta sobre la lucha contra las amenazas híbridas. Una respuesta de la Unión Europea. (JOIN (2016) 18). Alta Representante de la Unión para Asuntos Exteriores y Política de Seguridad. Recuperado de https://eur-lex.europa.eu/legal-content/ES/ TXT/PDF/?uri=CELEX:52016JC0018\&from=es

COMISIÓN EUROPEA (2016b). Pluralismo y democracia de los medios de comunicación. Eurobarómetro Especial 452. Recuperado de https://ec.europa.eu/digital-single-market/en/news/media-pluralismand-democracy-special-eurobarometer-452

COMISIÓN EUROPEA (2018). Comunicación de la Comisión al Parlamento Europeo, al Consejo, al Comité Económico y Social Europeo y al Comité de las regiones. La lucha contra la desinformación en línea, un enfoque europeo. $\operatorname{COM(2018)} 236$ final. Recuperado de https://eur-lex.europa.eu/ legal-content/ES/TXT/PDF/?uri=CELEX:52018DC0236\&from=EN

COMISIÓN EUROPEA (2019). El código de buenas prácticas contra la desinformación cumple un año: las plataformas en línea presentan informes de autoevaluación. (Statement/19/6166). Recuperado de https://ec.europa.eu/commission/presscorner/detail/es/statement_19_6166

COMISIÓN EUROPEA (2020a). Conclusiones del Consejo sobre la alfabetización mediática en un mundo en constante trasformación (DOC 193 de 9.06.2020). Recuperado de https://eur-lex.europa.eu/ legal-content/ES/TXT/PDF/?uri=CELEX:52020XG0609(04)\&from=FI

COMISIÓN EUROPEA (2020b). El efecto de la digitalización en nuestra vida diaria. Eurobarómetro especial 503. Recuperado de https://data.europa.eu/euodp/es/data/dataset/S2228_92_4_503_ENG

EUROPEAN COMMISSION (2018a). Synopsis report of the public consultation on fake news and online disinformation. Recuperado de https://ec.europa.eu/digital-single-market/en/news/synopsisreport-public-consultation-fake-news-and-online-disinformation

EUROPEAN COMMISSION (2018b). A multi-dimensional approach to disinformation: report of the independent High-level Group of fake news and online disinformation. Luxembourg: Publications Office of the European Union.

EUROPEAN COMMISSION (2019a). «10 ways the EU is fighting disinformation». European Commission Official Medium account. Recuperado de https://europeancommission.medium.com/10-ways-theeu-is-fighting-disinformation-f07fca60e918

EUROPEAN COMMISSION (2019b). Rapid alert System: strengthening coordinated and joint responses to disinformation. Recuperado de https://eeas.europa.eu/sites/eeas/files/ras_factsheet_march_2019_0.pdf 
EUROPEAN COMMISSION (2020). Commission Staff working document. Assessment of the Code of Practice on Disinformation- Achievements and áreas for further improvement. (SWD (2020) 180 final.

EUROPEAN EXTERNAL ACTION SERVICE (2019). Action plan against disinformation-Report on progress. Recuperado de https://ec.europa.eu/digital-single-market/en/news/action-plan-againstdisinformation-report-progress

FEIJÓO, Claudio (2020). «Conversamos con el catedrático Clauido Feijóo: hacia un nuevo enfoque de diplomacia tecnológica». OdiselA, 22 de junio. Recuperado de https://cutt.ly/tjzyCKg

GDI (2019). The quarter billion dollar question: how is disinformation gaming ad tech? London: Global Disinformation Index. Recuperado de https://disinformationindex.org/wp-content/uploads/2019/09/ GDI_Ad-tech_Report_Screen_AW16.pdf

GDI (2020). Ad-funded Covid-19 disinformation: money, brands and tech. London: Global Disinformation Index. Recuperado de https://disinformationindex.org/wp-content/uploads/2020/07/GDI_Adfunded-COVID-19-Disinformation-1.pdf

KATSIRIKOU, Anthi, RIGAKOU, Vasiliki y GIANNOPOULOU, Aggeliki (2019). «European Documentation Centres in recent financial crisis: Good practices and lessons learned». En International Federation of Library Associations. World Library and Information Congress 2019. Recuperado de http://library. ifla.org/2515/1/185-katsirikourigaikou-en.pdf

MACKEY, Thomas P. y JACOBSON, Trudi E. (2014). Metaliteracy: reinventing information literacy to empower learners. Chicago: ALA Editions.

NIÑO GONZÁLEZ, José Ignacio, BARQUERO CABRERO, Mario y GARCÍA GARCÍA, Enrique (2017). «Opinión pública e infoxicación en las redes: los fundamentos de la post-verdad». Vivat Academia, Revista de Comunicación, 139, 83-94. Recuperado de http://www.vivatacademia.net/index.php/ vivat/article/view/1083

PINTO-SANTOS, Alba Ruth, DÍAZ CARREÑO, Jarold Antonio y SANTOS-PINTO, Yorly Andrea (2018). «Infoxicación y capacidad de filtrado: desafíos en el desarrollo de competencias digitales». Revista Científica electrónica de educación y comunicación en la sociedad del conocimiento, I(18). Recuperado de http://eticanet.org/revista/index.php/eticanet/article/view/159/135

QIU, Xiaoyan, OLIVEIRA, Diego F. M., SHIZARI, Alireza Sahami, FLAMMINI, Alessandro y MENCZER, Filippo (2017). «Limited individual attention and online virality of low-quality information». Nature Human Behaviour, 1(0132). Recuperado de https://www.nature.com/articles/s41562-017-0132

RAMÓN REYERO, Eva (2020). La Unión Europea a un click. Recursos y fuentes de información. Madrid: Centro de Documentación Europea Universidad Francisco de Vitoria. Recuperado de https:// centro-documentacion-europea-ufv.eu/wp-content/uploads/2020/09/La-UE-a-un-click-vdef.pdf

RODRÍGUEZ PÉREZ, Carlos (2019). «No diga fake news, di desinformación: una revisión sobre el fenómeno de las noticias falsas y sus implicaciones». Comunicación, 40, 65-74.

SAMPLE, Angela (2020). «Historical development of definitions of information literacy: A literatura review of selected resources». The Journal Academic Librarianship (en prensa). Recuperado de https:// digitalshowcase.oru.edu/cose_pub/109/

STELETTI, Monica y MESTRE LAMPREIA, Eulália (2017). «How to find it? EU documentation: perspectives from a reserach library». En World Library and Information Congress. International Federation of Library Associations. Recuperado de https://www.ifla.org/ES/publications/node/11891

TERÁN GONZÁLEZ, Elena (2019). Desinformación en la UE: ¿amenaza híbrida o fenómeno comunicativo? Evolución de la estrategia de la UE desde 2015. Documento de Trabajo. Serie Unión Europea 
y Relaciones Internacionales, $\mathrm{n}^{\circ}$ 89/2019. Madrid: Instituto Universitario de Estudios Europeos Universidad CEU San Pablo

UNIÓN EUROPEA (1999). Recopilación de los Tratados. Luxemburgo: Oficina de Publicaciones Oficiales de las Comunidades Europeas.

VOSOUGHI, Soroush, ROY, Deb y ARAL, Siman (2018). "The spread of true and false news online». Science, 359 (6380), 1146-1151. Recuperado de https://science.sciencemag.org/ content/359/6380/1146.full

VUORIKARI, Riina, PUNIE, Yves, CARRETERO GÓMEZ, Stephanie y VAN DEN BRANDE, Godelieve (2016). DigComp 2.0: The Digital competence framework for citizens. Update Phase 1: the conceptual reference model. Luxembourg: Publications Office of the European Union. Recuperado de https://cutt.ly/njzdVOk 